\title{
The Information System Of Office Correspondence And Online Disposition
}

\author{
Anita Ahmad Kasim ${ }^{\text {a,1,* }}$, Muhammad Bakri ${ }^{\text {b,1 }}$, Wirdayanti ${ }^{\text {a,2 }}$ \\ ${ }^{\text {a }}$ Department of Information Technology, Faculty of Engineering, Tadulako University \\ ${ }^{\mathrm{b}}$ Department of Architecture, Faculty of Engineering, Tadulako University \\ 1nita.kasim@gmail.com*; ${ }^{2}$ embakri@gmail.com; ${ }^{3}$ wirda.ida28@gmail.com \\ *corresponding author
}

\section{ARTICLE INFO}

Article history

Received

Revised

Accepted

Keywords

Information System

Correspondence

Disposition

Online

\begin{abstract}
Introduction: The problems of correspondence efficiency and effectiveness as well as disposition in LPPM Universitas Tadulako related to manual management can be overcome by utilizing the current advanced technology. One of the utilization of advanced information technology is by using correspondence application systems and online disposition. The correspondence management system is performed systematically and paperless, which is also a solution during Covid-19 pandemics where all office administration is done from home Method: The developmental system method used was the Prototype model. A prototype model is a method of the system-making process made structurally and has stages that must be done in its making. Results and Discussion: This research was done to build online correspondence and disposition management system in LPPM instances of LPPM Universitas Tadulako. The information system of Office Correspondence and Online Disposition of the Research and Community Dedication Institution (LPPM) of Universitas Tadulako will form a paperless work system in the institution so that it is able to improve the effectiveness of administration management performance in LPPM in the effort to improve the quality of research and community dedication in Universitas Tadulako Conclusion: This letters archive application is made to make it easier and streamline the time in filing the letter which has been done manually before and has a little bit long time in its previous implementation. The working system of this application is not really difficult so that the staff does not find any difficulties in using the application.
\end{abstract}

This is an open-access article under the CC-BY-SA license.

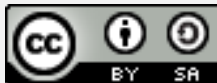

\section{Introduction}

The development of the era is accompanied by the application of bureaucratic reform application which requires every educational institution's activities, including university, to run efficiently and effectively. This needs transformation from the conventional or manual system into an automatics system, online and paperless. One of the activities that must be transformed is the institutional activities which are related to correspondence and disposition activities. Correspondence and disposition activities become activities that cannot be separated from daily activities in an educational institution (university). 
Correspondence and disposition activities still become written communication media recognized officially between governmental institutions and educational institutions (university). In addition to institutions and universities, correspondence and disposition activities are also performed in branches or working units in governmental institutions or universities.

Correspondence and disposition activities still use a manual system causing the letters to document to pile up, so the disposition process is inhibited. The instruction that can be done immediately is delayed since it is not accepted immediately by the field executor. The difficulties in finding letters needed also worsen the situation. The increased use of paper also burdens the institutions' finances. The correspondence and disposition activities in Universitas Tadulako, especially in Research and Community Dedication Institution (LPPM), currently used the old method, which is conventional and manual method. The use of such a conventional method is imbalanced since the volume and intensity of correspondence are getting an increase; thus, it requires quickness and punctuality. Furthermore, the manual method also emerges several issues, including the tardiness of letters accepted leads to the inhibition of the disposition process, the difficulties in checking the incoming and outgoing letters because it needs a long time to find the letters. Therefore, it is not efficient. In addition, universities must need more human resources who are obliged to deliver the letters so that it reaches the target fast.

The issues in efficiency and effectiveness of correspondence and disposition in LPPM Universitas Tadulako related to the management, which is still conducted manually, can be overcome by utilizing the current advanced technology. One of the utilization is by using correspondence application system and online disposition. An automatic, online, and paperless correspondence management system becomes one of the solutions during Covid19 pandemics, where all office administration management is done from home.

Based on those problems, a research entitled SIPAKPOS: The Information System of Office Correspondence and Online Disposition of Research and Community Dedication Institution of Universitas Tadulako was performed. This research aimed to build an information system that is capable of regulating the correspondence and disposition online so that effective and efficient correspondence administration is created.

The urgency of the research on the information system of official correspondence and online disposition of Research and Community Dedication Institution of Universitas Tadulako includes:

1. The management of Electronic Letter Achieves: since it has been done electronically and stored in the server, then it should not be a worry to lose the letter. In addition, it also makes it easier to track the incoming/ outgoing letter

2. Disposition can be done anywhere and anytime: by applying the application of Correspondence and Online Disposition, the head of LPPM can directly dispose of the incoming letter through a smartphone.

3. Disposition tracking becomes easier: by applying such correspondence and disposition system, the disposition giver (the Head of LPPM) can directly track and monitor how far the disposition has been done so that there is no reason by the disposition recipient to not perform the duty.

4. Coordination between Sections/Units becomes easier: by the availability of eOffice applications for correspondence and disposition, the incoming and outgoing information and disposition becomes fast and makes it easier for the staff to coordinate with the other sections/units in the process of disposition implementation. 
5. Saving the Paper Budget: by applying the e-office application for correspondence and disposition, the paper budget can be saved since all of the activities are done through application and support the government program in decreasing the use of paper or usually called as " Go Paperless."

6. Become a solution when disaster or pandemics occur so that working in the office is impossible and employees should work from home

\section{Method}

The developmental system method used was the prototype model, which is illustrated in Fig 1. prototype model is a method of system making process made structurally and has stages that must be done in its making. However, if the final process states that the system made is not complete yet or still has a weakness, then the system will be evaluated and start from the beginning again. The prototyping approach is an iterative process involving a close working relationship between the designer and the user. The explanation is as follow:

1. User Requirements

This stage was used to determine the general purpose, needs knowing, and illustration of parts needed in the future.

2. Design

The design was dined fast and represented all software aspects known, and this design becomes the basic of making the prototype.

3. The evaluation of Prototype

The prototype that has been made was evaluated to make the software needs clearer.

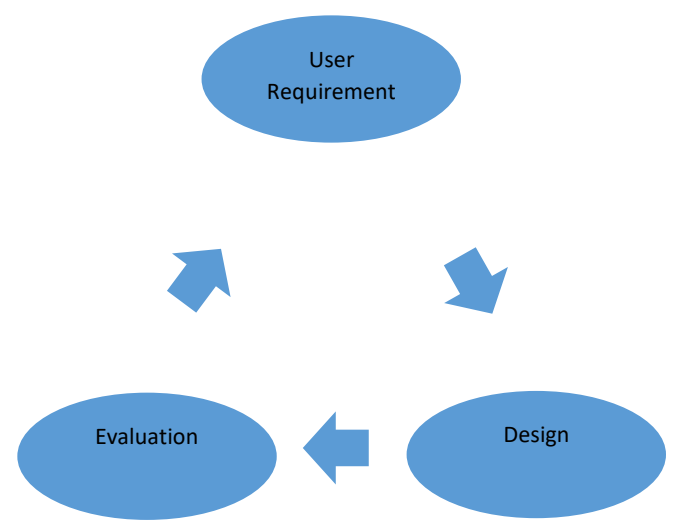

Fig 1. Prototype Model 
The data collection technique used was observation to obtain data needed in the making of the management information system of official correspondence and online disposition. The researchers conducted an observation to see the correspondence at the office and collected the data from the office staff regarding the correspondence and disposition.

The stages done during the practical work are as follow:

1. The observation concerning the need of the institution, especially in the field related to informatics.

2. It is collecting data to meet the system need that will be made.

3. Designing system in accordance with the LPPM need

4. $\mathrm{s}$ and making the management information system of correspondence and online disposition.

5. I was testing the system that has been made.

6. The try-out of the system use.

Based on the observation result and the issues found in the field, then a more efficient correspondence archive application was made. The following is the stage of the application shown in Figure 2.

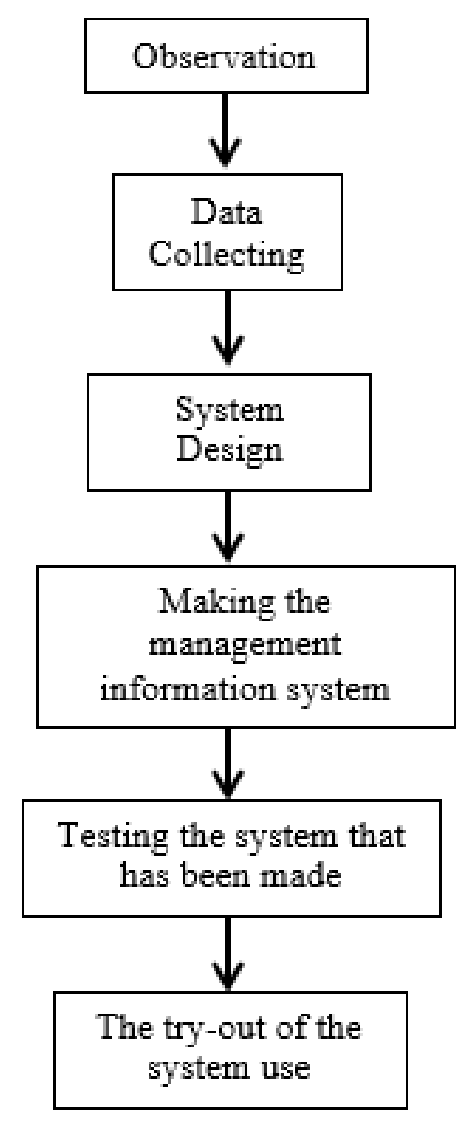

Fig 2. Research Process Stages 


\section{Results and Discussion}

The context diagram of the DFD Level 1 can be seen in Fig. 3 and Fig. 4.

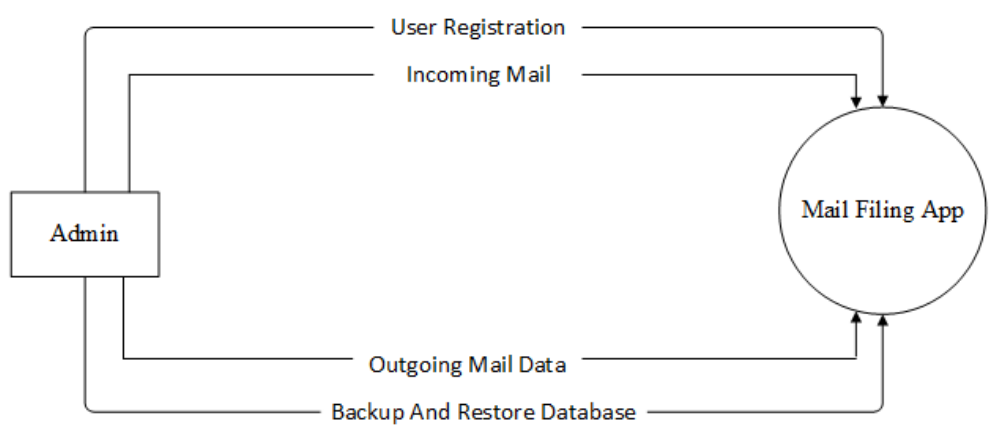

Fig 3. The Context Diagram

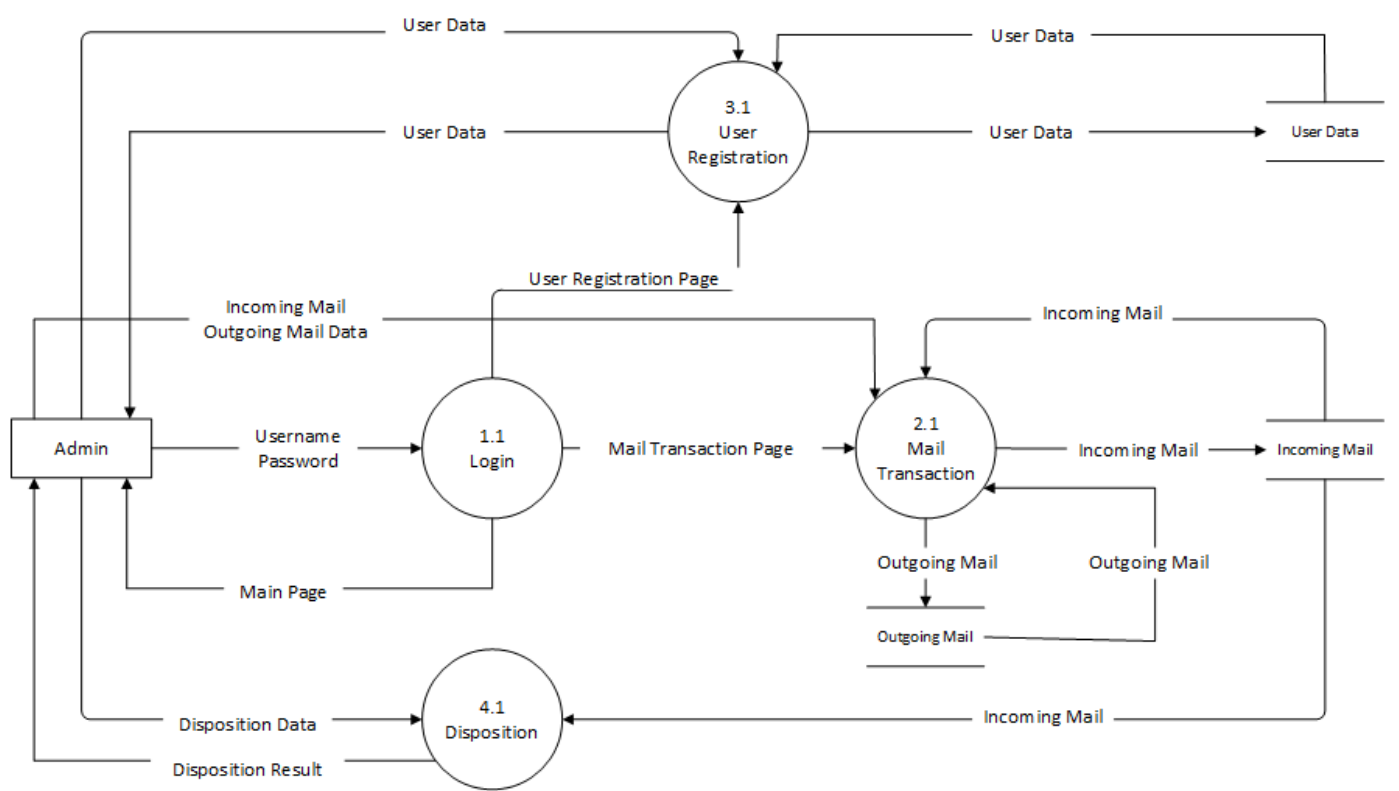

Fig 4. The Data Flow Diagram Level 1

The Use Case, The Activity Diagram, and The Sequence Diagram can be seen in Fig. 5, Fig. 6, and Fig. 7. 


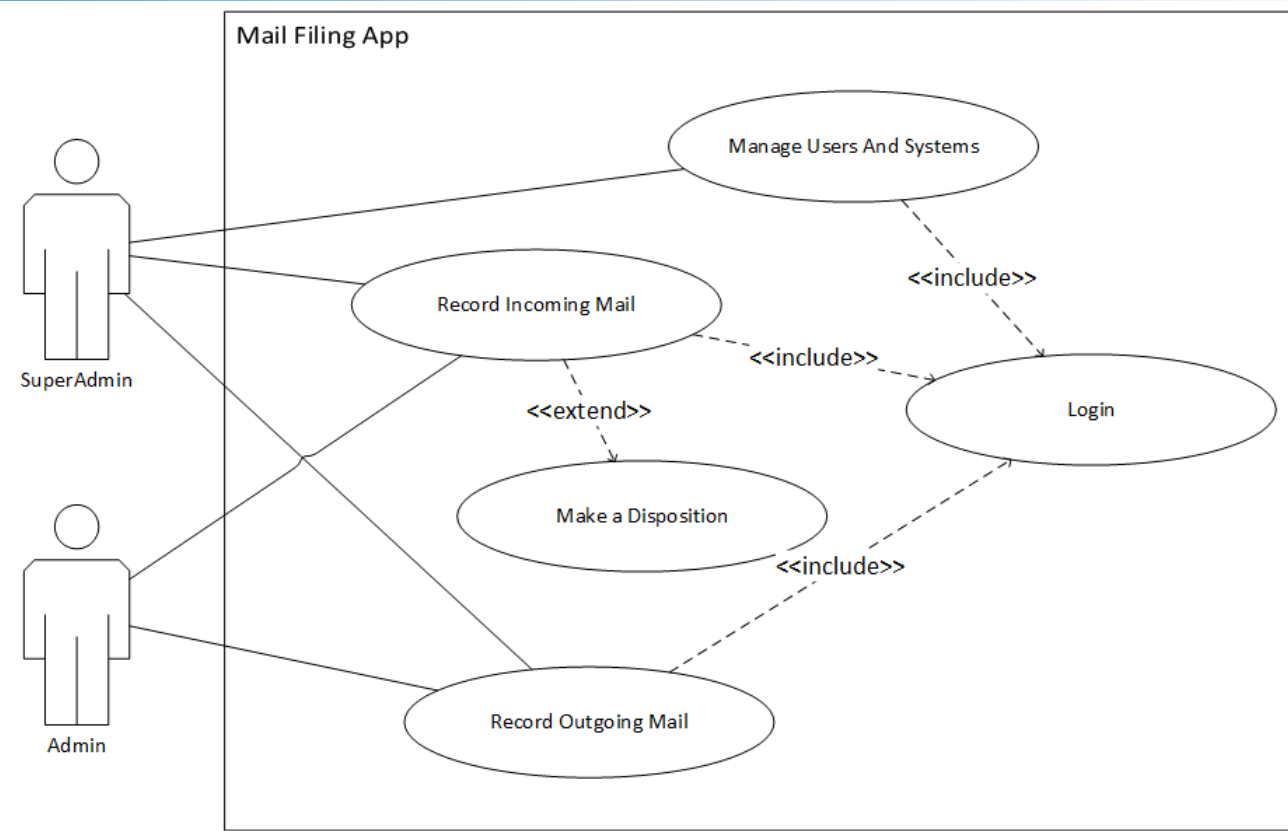

Fig 5. Use Case Sistem

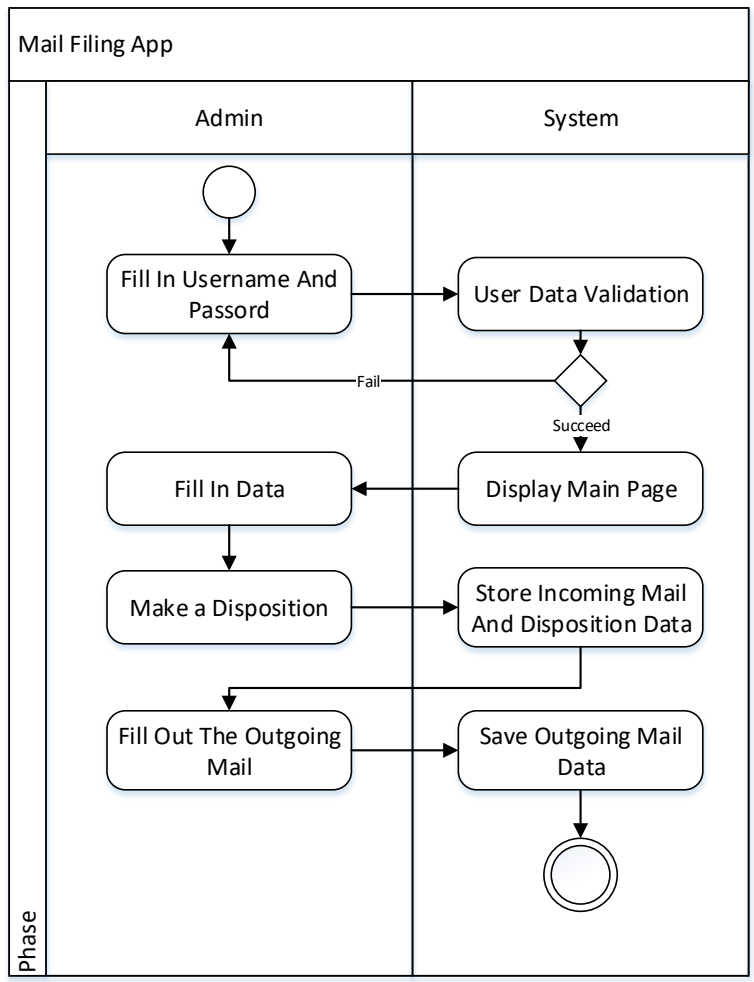

Fig. 6. Activity Diagram 


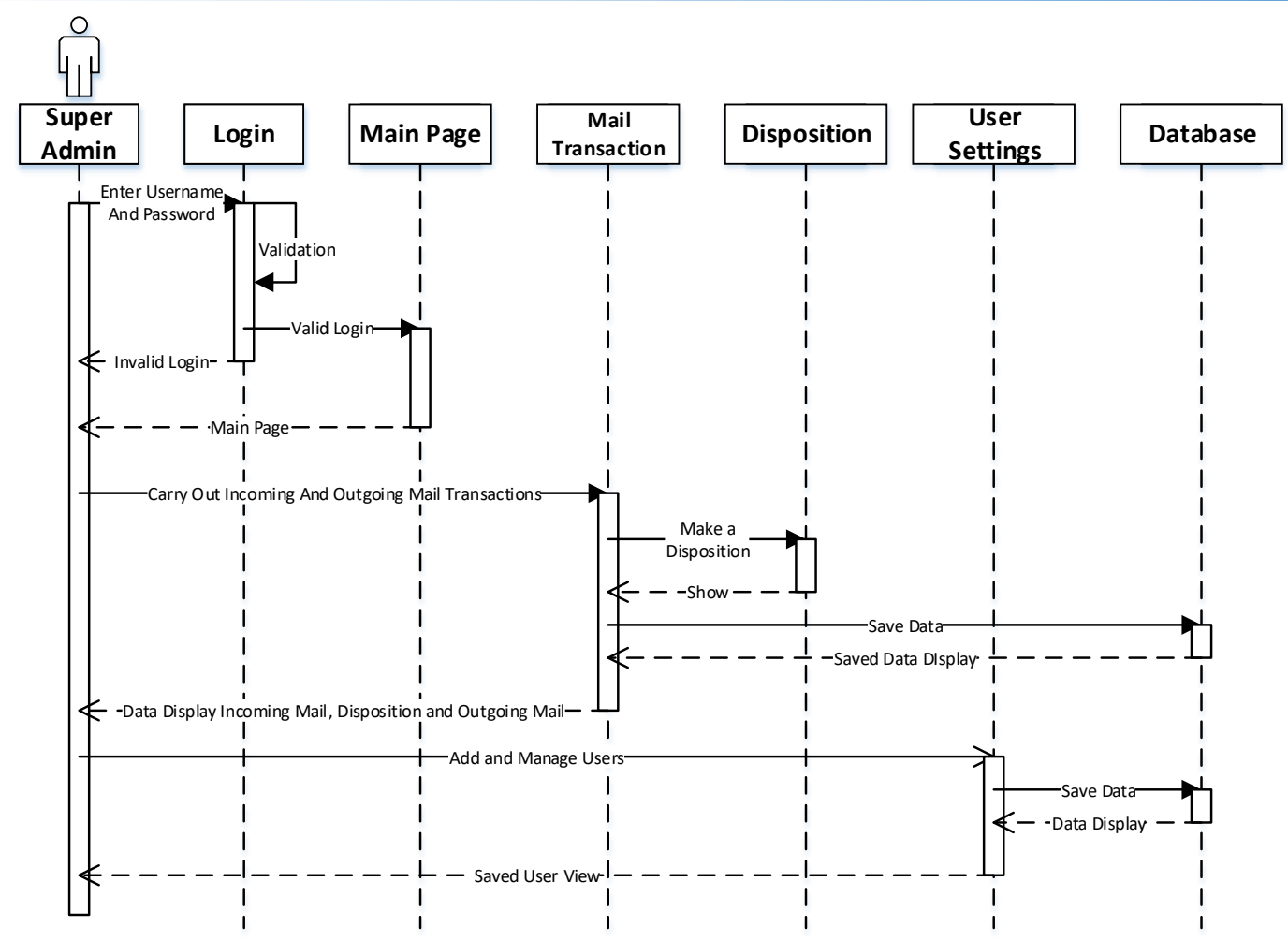

Fig. 7. The Sequence Diagram

In the database, there are tables used to store the data, which is divided into several categories. In the database, along with its structure. The first one is the user table. The user table is a table to store the data related to the system user. In the database, there are several tables as the place to store the data. The data of incoming letters are also stored in a table, and such a table contains data related to incoming letters.

\section{Conclusion}

This letters archive application is made to make it easier and streamline the time in filing the letter, which has been done manually before and has a little bit long time in its previous implementation. The working system of this application is not really difficult so that the staff does not find any difficulties in using the application. The application user only needs to fill the data, and from then, a disposition is made and can be directly printed.

\section{Acknowledgment}

The researcher would like to thank all those who have helped, especially the leaders of Tadulako University who have provided funds for this research.

\section{References}

Astola, P. J., P. Rodríguez, J. Botana, and M. Marcos. 2017. "A Paperless Based Methodology for Managing Quality Control. Application to Supplier Company." Procedia Manufacturing 13: 1066-73. https://doi.org/10.1016/j.promfg.2017.09.135.

Failte Ireland. 2013. "Introduction to the Web: A Beginner's Guide to Understanding and Using the Web.": 1-18.

Kusnendi. 2014. “Konsep Dasar Sistem Informasi.” Konsep Dasar Sistem Informasi: 1-36.

Liu, Guilong, Yanbin Feng, and Jitao Yang. 2020. “A Common Attribute Reduction Form for 
Information Systems.” Knowledge-Based Systems 193: 105466. https://doi.org/10.1016/j.knosys.2019.105466.

Rahmah, Dewi Leyla. 2014. "Perancangan Aplikasi Sisitem Perpustakaan Berbasis Web Pada PT. Dwi Pilar Pratama." Faktor Exacta 3(3): 282-92. 